\title{
Effectiveness and Feasibility of Post- Exacerbation Pulmonary Rehabilitation (PEPR) in a Real-World Clinical Setting: A Quality Improvement Project
}

\author{
Agnieszka Lewko', Stephanie K Mansell², Melanie Irvin-Sellers ${ }^{3}$ \\ ${ }^{1}$ Faculty of Health, Social Care and Education, Kingston University and St. George's University of London, \\ United Kingdom \\ 2Therapies Department, Royal Free London NHS Foundation Trust, United Kingdom \\ ${ }^{3}$ Respiratory Medicine, Ashford and St. Peter's Hospitals NHS Foundation Trust, United Kingdom
}

Correspondence to: Agnieszka Lewko, email: a.lewko@sgul.kingston.ac.uk

DOI: https://doi.org/10.5114/phr.2021.109027

Received: 19.02.2021 Reviewed: 19.03.2021 Accepted: 19.03.2021

\begin{abstract}
Background: The implementation of Post-Exacerbation Pulmonary Rehabilitation (PEPR) in clinical practice has some challenges.
\end{abstract}

Aims: The aim of this project was to evaluate the feasibility and effectiveness of PEPR in practice.

Material and methods: Data were collected prospectively from 112 patients referred to PEPR. Healthcare (HC) utilization was measured by 30- and 90-day readmissions (30R\&90R) and emergency departments visits (30ED\&90ED), and compared between PEPR completers, drop-outs, and decliners (Chi-squared test). Incremental cost effectiveness (ICER) was calculated. The Incremental Shuttle Walk Test (ISWT), the Chronic Obstructive Pulmonary Disease (COPD) Assessment Test (CAT), the Breathing Problem Questionnaire (BPQ), and the Hospital Anxiety and Depression Score (HADS) were all assessed pre- and post-PEPR.

Results: Compared to PEPR completers $(\mathrm{n}=38)$, PEPR decliners $(\mathrm{n}=$ 59) and drop-out patients $(\mathrm{n}=15)$ had more 30\&90ED attendances ( $8 \%$ vs. $24 \%$ and $47 \% ; \chi^{2}=4.31, p=0.04$ and $\chi^{2}=9.60, p=0.002$, respectively), 30R (5\% vs. $20 \%$ and $27 \% ; \chi^{2}=4.67, \mathrm{p}=0.03$ and $\chi^{2}$ $=4.44, \mathrm{p}=0.04$, respectively), and 90R (3\% vs. $24 \%$ and $40 \% ; \chi 2=$ 7.93, $\mathrm{p}=0.005$ and $\chi 2=12.39, \mathrm{p}<0.001$, respectively). The ICER was $£ 7,248(€ 8,394)$ in favor of the PEPR-completer group. There were
Key words

rehabilitation, pulmonary disease, Chronic Obstructive Pulmonary Disease (COPD), patient readmission, outcome assessment (healthcare), quality of care 
significant improvements of mean difference in all assessment tests for patients who completed PEPR (95\% CI), with the exception of their HADS score. In the ISWT, patients had a mean distance of $50.3 \mathrm{~m}$ (29.7 $\mathrm{m}$ pre-PEPR and $70.9 \mathrm{~m}$ post-PEPR; $\mathrm{p}<0.001$ ); patients had a mean score of -3.6 on the BPQ (-1.7 pre-PEPR, -5.4 post-PEPR; $\mathrm{p}=0.001)$, and a mean CAT score of -4.3 (-1.9 pre-PEPR, -6.7 post-PEPR; $\mathrm{p}=0.002$ ).

Conclusion: : PEPR is feasible and cost-effective. Several factors should be considered for $\mathrm{HC} \mathrm{qu}^{-}$ ality and effectiveness improvement.

\section{Introduction}

One in eight emergency admissions in the UK are due to acute exacerbations of Chronic Obstructive Pulmonary Disease (AECOPD), with a cost to the National Health Service (NHS) of $£ 805-$ 870 million a year [1]. Of these who are admitted to hospital with AECOPD, 7\% will die in hospital, $13.9 \%$ will die within 90 days, and $25 \%$ will die within one year $[1,2]$. The consequences of an AECOPD are reduced physical activity, muscle function, exercise capacity, and quality of life (QoL) [3-5], as well as increased mortality and risk of readmission [6-7].

Post-Exacerbation Pulmonary Rehabilitation (PEPR) following an AECOPD admission has similar benefits to elective pulmonary rehabilitation (PR) in terms of health-related outcome measures [8]. Results from PEPR randomized controlled trials (RCTs) have demonstrated that it results not only in improved exercise tolerance and QoL, but also in reduced hospital readmissions $[9,10]$. Therefore, current guidelines recommend PEPR in the management of AECOPD $[1,2,11]$. However, participants in PEPR trials may not be representative of real-world patients, and whether results of RCTs can be replicated in clinical practice is yet to be demonstrated.

Concerns have been expressed regarding the feasibility of PEPR in real-world clinical situations due to patient recruitment and uptake difficulties [12]. For example, in one RCT it took three years to recruit 60 patients [9]. More concerning are figures from both clinical practice and a cluster analysis reporting that only $10-23 \%$ of patients admitted with an AECOPD completed PEPR [13,
14]. Patients will cite many reasons for non-participation in PEPR, including problems with transport, logistics, or poor recall of information provided during hospital admission $[15,16]$. The impact of admission on psychological health can also be such that patients are reluctant to attend outpatient settings or engage in rehabilitation [12]. It is difficult to ascertain whether observed healthcare (HC) utilization reductions are primarily due to physiological adaptations, improved self-management, or psychological support through regular clinician contact.

In June 2013, our NHS general hospital in South East England, United Kingdom, served a population of approximately 400,000, with an average of 42 admissions per month due to an AECOPD. For these AECOPD admissions, the average length of stay was 7.7 days [17]. While average length of stay was comparable to other similar acute hospital trusts in the same geographical area, the $30-$ and 90-day readmission rates were higher at our hospital [17]. This discrepancy prompted consideration of quality improvements that could help to reduce readmission rates. Funding was secured from the chief executive's innovation fund to pilot PEPR as a quality improvement project to assess if PEPR could reduce readmission rates for patients admitted with an AECOPD.

\section{Aims}

The aim of the study was the qualitative and quantitative analysis of single-leg jumping in children aged 7-13 years. The subject of the study was to determine variants of the activity of the sup- 
porting and unloaded lower limb and compensatory synkinesis, the number of jumps in selected time intervals for the right and left lower limbs, and qualitative and quantitative changes in particular age groups.

\section{Material and methods}

\section{Study design}

Data were collected prospectively from those referred to PEPR between December 2013 and November 2014. This study was a service quality improvement project and thus ethical opinion from a research ethics committee was not sought. The project was reviewed and approved by the Ashford and St. Peter's Hospitals (ASPH) NHS Foundation Trust chief executive innovation fund panel.

\section{Plan, Do, Study, Act (PDSA) cycle}

Quality improvement Plan, Do, Study, Act (PDSA) cycles provide a framework for testing, developing, and implementing change [18]. The PDSA cycle in this project was as follows:

P: Assess the feasibility of PEPR in a real-world clinical setting.

D: Launch PEPR classes with small numbers of patients to allow for testing.

S: Collect data, including referral numbers, outcome measures, and healthcare utilization.

A: Identify and consider modifications required, as seen in the discussion section of this paper.

\section{PEPR program provision}

Subjects undertook a minimum six-week outpatient PEPR program with two supervised and one unsupervised (home exercise) sessions per week. For patient convenience and to maximize attendance, PEPR was organized as a "rolling" program, and patients who missed session(s) could continue beyond six weeks until they had attended 12 supervised sessions over a maximum of 10 weeks. Each session consisted of a 1-hour exercise training session and a 30-minute education session. The exercise training was designed as circuit training and consisted of an individually tailored program of aerobic and strength training. Endurance or interval trainings were used to achieve an exercise intensity of $60-85 \%$ VO2 peak (Peak Oxygen consumption), based on the Incremental Shuttle Walk Test (ISWT). High intensity exercise was promoted, and gradual progression was encouraged each week. Aerobic training included cycling, walking, and step climbing. Additionally, patients were encouraged to increase their walking distance using goal setting. Education sessions were delivered by a multidisciplinary team and covered topics as per current guidelines [11, 19]. If required, a delta rollator or walking stick was provided and supplemental ambulatory oxygen was prescribed. Free transport was provided for those requiring it.

\section{Participants}

Patients admitted with an acute exacerbation of a chronic respiratory condition were eligible for PEPR and were referred at discharge from the hospital to an outpatient PEPR program. Patients were ineligible for PEPR if they had unstable angina, arterial fibrillation, or other unstable cardio-vascular conditions, severe musculoskeletal problems affecting ability to exercise, were unable to attend a hospital outpatient program, or were under end-of-life care. Patients who declined to attend PEPR or who did not attend their assessment appointment were considered "decliners." Patients who agreed to attend the PEPR program underwent an individual baseline assessment. After attendance of 12 rehabilitation sessions, patients were invited for a reassessment session within one week of completion. Those unable to complete a minimum of $75 \%$ of the program (9 sessions) were classified as "drop-out."

\section{Outcome measures}

Age, gender, and history of previous admissions were recorded. Data on $\mathrm{HC}$ utilization were collected from hospital patient administration systems and discharge summaries. Number of emergency department (ED) visits plus number and subsequent length of hospital readmissions at 30-and 90-days post-hospital discharge were recorded. The following measures were recorded 
before and after PEPR: Forced expiratory volume in one second (FEV1) and forced vital capacity (FVC) were assessed according to the American Thoracic Society (ATS) and European Respiratory Society (ERS) standards of spirometry using a spirometer (Vitalograph Model 6000; Vitalograph Ltd, Maids Moreton, Bucks, UK) [20]; exercise tolerance was assessed using the ISWT and the Endurance Shuttle Walk Test (ESWT); and health-related QoL was measured using the Breathing Problem Questionnaire (BPQ) [21], COPD Assessment Test (CAT), and the Hospital Anxiety and Depression Scale (HADS). As part of the evaluation of the PEPR program, patients were also asked to complete an in-house patient satisfaction survey.

\section{Statistical analysis}

Demographics were presented using descriptive statistics. Data were analyzed in groups of PEPR completers, PEPR drop-outs, and PEPR decliners. Patients who failed to attend an initial assessment were combined with those who initially declined to form the decliner group. Differences in baseline characteristics between the groups were assessed using ANOVA. The number of readmissions and ED attendances in each group were compared using a Chi-squared test. Data pre- and post-PEPR were analyzed using a paired t-test for parametric variables and a Wilcoxon si- gned-rank test for non-parametric variables. For all analyses, a p-value of 0.05 was used as statistically significant. All statistical analyses were carried out in SPSS v23 (IBM statistics, Armonk, US).

\section{Cost effectiveness analysis}

A cost-benefit analysis was carried out from an NHS perspective. A comparator of 90-day readmission and subsequent bed days was chosen. An assumed bed day cost of $£ 302$ was used. Cost variables input into the model were staffing and equipment costs of the PEPR program. An incremental cost effectiveness (ICER) was calculated [25]. As this model only allows two groups, the decliner group was compared to a combined PEPR-completer and drop-out group.

\section{Results}

\section{Participants}

There were 112 PEPR referrals received. Following first telephone contact, 50 patients declined PEPR. Figure 1 displays the recruitment pathway of PEPR referrals. The participant mean (SD) age was $72( \pm 9.6)$ years, and 42 participants were male. The majority of patients had a diagnosis of COPD, but patients with other diagnoses were referred $(n=10)$, including bronchiectasis and asthma. Baseline characteristics are displayed in Table 1.

112 referrals

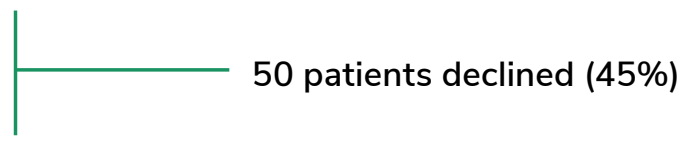

62 offered initial assessment (55\%)

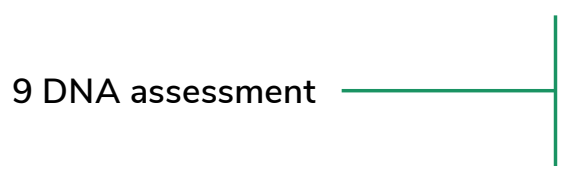

53 attended initial assessment

(47\% of 112 )

15 did not complete (28\%)

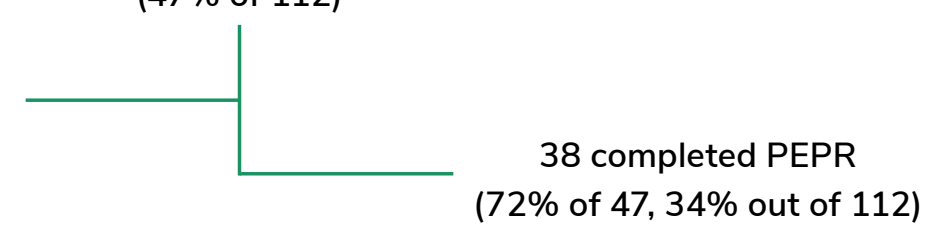


Table 1. Baseline characteristic of patients referred to PEPR.

\begin{tabular}{|c|c|c|c|c|}
\hline Variable & $\begin{array}{l}\text { PEPR Com- } \\
\text { pleters } \\
(n=38)\end{array}$ & $\begin{array}{l}\text { PEPR } \\
\text { Drop-out } \\
(n=15)\end{array}$ & $\begin{array}{l}\text { Declined } \\
(n=59)\end{array}$ & $p$-value \\
\hline Age (years) & $73.1(9.8)$ & $71.1(10.2)$ & $74.1(9.2)$ & 0.31 (ANOVA) \\
\hline $\mathrm{FEV}_{1}(\mathrm{~L})$ & $0.94(0.39)$ & $0.82(0.31)$ & - & 0.30 (t-test) \\
\hline pred. $\mathrm{FEV}_{1}(\%)$ & $46.6(22.3)$ & $39.2(13.0)$ & - & 0.54 (t-test) \\
\hline Length of stay (days) & $5.7(4.2)$ & $5.2(3.8)$ & $6.2(4.3)$ & 0.70 (ANOVA) \\
\hline $\begin{array}{l}\text { Number of admissions } \\
\text { in previous } 6 \text { months }\end{array}$ & $0.94(0.9)$ & $1.7(1.4)^{\mathrm{a}}$ & $1.2(1.3)^{\mathrm{b}}$ & $\begin{array}{l}0.69 \text { (ANOVA) } \\
{ }^{\mathrm{a}} 0.03 \text { t-test } \\
{ }^{\mathrm{b}} 0.001 \text { t-test }\end{array}$ \\
\hline
\end{tabular}

Abbreviations: PEPR - Post-Exacerbation Pulmonary Rehabilitation, FEV1- Forced Expiratory Volume in one second.

\section{Healthcare utilization and cost effectiveness}

Fewer 30- and 90-day readmissions were observed in patients who completed PEPR compared to both the drop-out group and those who declined to attend (Table 2). The same trend was observed in 30-day ED attendances, with a clinically meaningful reduction in 90-day ED attendances. When patients were readmitted, those who had completed PEPR had a reduced length of stay compared to those who had dropped out or declined to attend PEPR (Table 3).
The fixed variable costs, that is the cost of running the program, equated to $£ 23,441$ ( $€ 27,147)$. The ICER calculated showed that PEPR was greater than standard care and equated to $£ 92.88$ (€107.56) per bed day. The total cost associated with length of stay for 90 days post-initial admission in the PEPR-completer and drop-out group was $£ 41,676$ ( $€ 48,265$ ), compared to $£ 48,924$ $(€ 56,659)$ in the PEPR-decliner group. Including the cost of the program, the total difference in bed day costs between the two groups was $£ 7,248$ $(€ 8,394)$.

Table 2. 30- and 90-day readmissions and emergency visits.

\begin{tabular}{|c|c|c|c|c|c|c|}
\hline \multirow[t]{2}{*}{$\begin{array}{l}\text { Healthcare } \\
\text { utilisation }\end{array}$} & $\begin{array}{l}\text { PEPR } \\
\text { decliners } \\
(n=59)\end{array}$ & $\begin{array}{l}\text { PEPR } \\
\text { drop-out } \\
(n=15)\end{array}$ & $\begin{array}{l}\text { PEPR } \\
\text { completers } \\
(n=38)\end{array}$ & $\begin{array}{l}\text { Completers } \\
\text { vs. Decliners }\end{array}$ & $\begin{array}{l}\text { Completers } \\
\text { vs. Drop-out }\end{array}$ & $\begin{array}{l}\text { Decliners- } \\
\text {-completer- } \\
\text { s-drop-out }\end{array}$ \\
\hline & & & & \multicolumn{3}{|l|}{ Chi-square } \\
\hline $\begin{array}{l}30 \text {-day } \\
\text { readmission }\end{array}$ & 12 (20\%) & $4(27 \%)$ & $2(5 \%)$ & $\begin{array}{l}\chi^{2}=4.67 \\
(p=0.03)\end{array}$ & $\begin{array}{l}\chi^{2}=4.44 \\
(p=0.04)\end{array}$ & $\begin{array}{l}\chi^{2}=9.1 \\
(p=0.07)\end{array}$ \\
\hline $\begin{array}{l}\text { 90-day } \\
\text { readmission }\end{array}$ & 14 (24\%) & $6(40 \%)$ & $1(3 \%)$ & $\begin{array}{l}\chi^{2}=7.93 \\
(p=0.005)\end{array}$ & $\begin{array}{l}\chi^{2}=12.39 \\
(p<0.001)\end{array}$ & $\begin{array}{l}\chi^{2}=5.97 \\
(p=0.003)\end{array}$ \\
\hline
\end{tabular}




\begin{tabular}{|c|l|l|l|l|l|l|}
\hline $\begin{array}{l}\text { 30-day ED } \\
\text { attendance }\end{array}$ & $14(24 \%)$ & $7(47 \%)$ & $3(8 \%)$ & $\begin{array}{l}\chi^{2}=4.31 \\
(\mathrm{p}=0.04)\end{array}$ & $\begin{array}{l}\chi^{2}=9.60 \\
(\mathrm{p}=0.002)\end{array}$ & $\begin{array}{l}\chi^{2}=5.34 \\
(\mathrm{p}=0.01)\end{array}$ \\
\hline $\begin{array}{l}\text { 90-day ED } \\
\text { attendance }\end{array}$ & $16(27 \%)$ & $6(40 \%)$ & $4(11 \%)$ & $\begin{array}{l}\chi^{2}=3.93 \\
(\mathrm{p}=0.048)\end{array}$ & $\begin{array}{l}\chi^{2}=5.61 \\
(\mathrm{p}=0.02)\end{array}$ & $\begin{array}{l}\chi^{2}=11.45 \\
(\mathrm{p}=0.05)\end{array}$ \\
\hline
\end{tabular}

Abbreviations: PEPR - Post-Exacerbation Pulmonary Rehabilitation, ED - Emergency Department.

Table 3. Comparison of healthcare utilisation and mortality between PEPR completers and decliners.

\begin{tabular}{|l|l|l|l|l|}
\hline & $\begin{array}{l}\text { PEPR } \\
\text { decliners } \\
(\mathbf{n = 5 9 )}\end{array}$ & $\begin{array}{l}\text { PEPR } \\
\text { drop-out } \\
(\mathbf{n = 1 5 )}\end{array}$ & $\begin{array}{l}\text { PEPR completers } \\
(\mathbf{n}=\mathbf{3 8})\end{array}$ & -value \\
\hline No. of readmissions & 26 & 10 & 3 & 0.003 \\
\hline Mean (SD) LOS on readmission & $9.5(8.7)$ & $14.9(14.5)$ & $5.3(1.2)$ & 0.33 \\
\hline Cumulative bed days & 162 & 119 & 19 & 0.003 \\
\hline Deaths & 5 & 4 & 2 & 0.08 \\
\hline
\end{tabular}

Abbreviations: PEPR - Post-Exacerbation Pulmonary Rehabilitation; LOS - Length of stay.

\section{Effectiveness of PEPR}

Thirty-eight patients in this study completed PEPR, equating to a PEPR completion rate of $34 \%$. Results for spirometry, exercise tolerance, health-related QoL, and mood pre/post PEPR for the completers group are displayed in Table 4. Altho- ugh there was not a statistically significant change in anxiety or depression scores, there was a clinically relevant decrease in the numbers of patients with abnormal or increased levels of anxiety and depression (Figure 2).

Table 4. Pre-post outcome measures for PEPR completers $(n=38)$.

\begin{tabular}{|l|l|l|l|l|}
\hline & $\begin{array}{l}\text { Pre PEPR } \\
\text { Mean (SD) }\end{array}$ & $\begin{array}{l}\text { Post PEPR } \\
\text { Mean (SD) }\end{array}$ & $\begin{array}{l}\text { Mean change } \\
95 \% \mathrm{Cl}\end{array}$ & p-value \\
\hline FEV1 (L) & $0.94(0.39)$ & $0.95(0.4)$ & $\begin{array}{l}0.02 \\
95 \% \mathrm{CI}(-0.03,0.07)\end{array}$ & 0.56 \\
\hline \% pred. FEV1 & $43.0(18.8)$ & $43.5(19.4)$ & $\begin{array}{l}0.44 \\
95 \% \mathrm{CI}(-2.3,3.2)\end{array}$ & 0.75 \\
\hline ISWT (m) & $215.3(119.8)$ & $265.5(124.1)$ & $\begin{array}{l}50.3 \\
95 \% \mathrm{CI}(29.7,70.9)\end{array}$ & $<0.001$ \\
\hline
\end{tabular}




\begin{tabular}{|l|l|l|l|l|}
\hline ESWT (min.) & $5.1(3.3)$ & $12.2(6.2)$ & $\begin{array}{l}27.1 \\
95 \% \mathrm{CI}(4.5,9.7)\end{array}$ & $<0.001$ \\
\hline CAT & $20.2(6.3)$ & $16.0(6.3)$ & $\begin{array}{l}-4.3 \\
95 \% \mathrm{CI}(-1.9,-6.7)\end{array}$ & 0.002 \\
\hline BPQ & $12.2(5.7)$ & $8.6(3.6)$ & $\begin{array}{l}-3.6 \\
95 \% \mathrm{CI}(-1.7,-5.4)\end{array}$ & 0.001 \\
\hline $\begin{array}{l}\text { HADS } \\
\text { anxiety }\end{array}$ & $8.1(4.8)$ & $6.6(3.6)$ & $\begin{array}{l}1.5 \\
95 \% \mathrm{CI}(-0.42,3.42)\end{array}$ & 0.12 \\
\hline $\begin{array}{l}\text { HADS } \\
\text { depression }\end{array}$ & $5.7(3.9)$ & $4.6(2.8)$ & $\begin{array}{l}1.1 \\
95 \% \mathrm{CI}(-0.4,2.5)\end{array}$ & 0.15 \\
\hline
\end{tabular}

Abbreviations: PEPR - Post-Exacerbation Pulmonary Rehabilitation, FEV1- Forced Expiratory Volume in one second, \% pred. - percent predicted, ISWT - Incremental Shuttle Walk Test, ESWT - Endurance Shuttle Walk Test, BPQ Breathing Problem Questionnaire, CAT - COPD Assessment Test, HADS - Hospital Anxiety and Depression Scale.

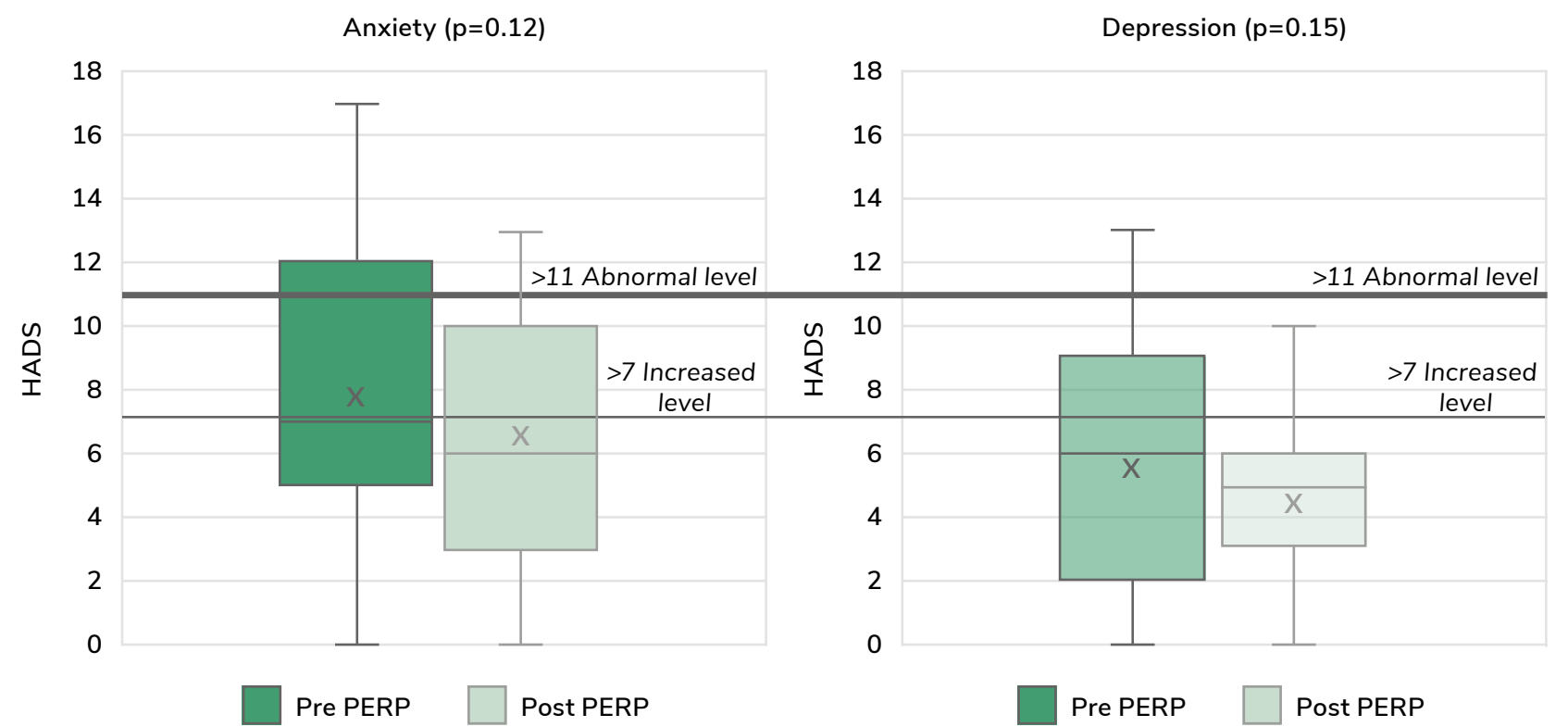

Figure 2. Change in HADS anxiety and depression after PEPR.

Abbreviations: HADS - Hospital Anxiety and Depression Scale, PEPR - Post-Exacerbation Pulmonary Rehabilitation. 


\section{Patients' perspective}

Patients' perspectives and opinions were captured from the patient satisfaction survey through open questions. Overall, all patients reported that they felt it was a good program. One patient reported that it was "A great follow up program after a hospital stay." Patients also found the education sessions very useful: "I was pleasantly surprised how informative the classes were," one patient reported. The patients also reported perceived benefits to their health and wellbeing, with comments such as: "These sessions have definitely improved my health and ability to walk further."

Twenty-seven patients (54\%) who declined to attend or dropped out from PEPR provided a reason for refusing. The top three reasons for declining were: did not want to exercise $(n=10,37 \%)$, concurrent medical conditions ( $n=5,19 \%)$, and feeling too unwell $(n=5,19 \%)$. Other reasons included the time commitment, distance to travel, and already partaking in regular exercise.

\section{Discussion}

\section{Healthcare utilization}

In line with previous RCT reports [8], this study observed that PEPR completers were less likely to attend the ED or be readmitted compared to PEPR decliners. A new observation made in this study concerned the shorter length of hospital stay following readmission for PEPR completers compared to those who declined the program. The cost-benefit analysis for PEPR was estimated, but it is beyond the scope of this study to include a perspective beyond that of our local general hospital. Additionally, the cost effectiveness analysis undertaken was unique to this PEPR program, and it is therefore unlikely to be appropriate to extrapolate to other services. Not all variable costs could be included: for example, the cost of ED attendances and readmission fines were not included. The program had capacity to accept 249 patients per year but did not run at full capacity. Additional cost effectiveness benefits may have been observed had PEPR uptake been higher. Overall, we found PEPR to be a co- st-effective modality in treating exacerbation of chronic lung disease resulting in hospitalization in our local population.

\section{Feasibility of PEPR}

The PEPR completion rate in this study (34\%) is comparable to that of previously published RCTs (42\% [12] and 38\% [11]). Our completion rate is also comparable with previously reported clinical studies with completion rates of $23-48 \%[13,22]$. The results of this quality improvement project and previous clinical studies suggest that in real-life clinical practice it is possible to achieve PEPR completion rates similar to those achieved under clinical trial conditions. What remains concerning is a low rate of referrals to PEPR. In our population, there were an estimated 500 AECOPD admissions per year, yet only 112 referrals to PEPR were received. The feasibility of PEPR is a frequently debated topic and it is yet to be established whether the perception of clinicians is a barrier to PEPR or whether PEPR is truly unacceptable to patients. Acceptability and feasibility of PEPR may not be generalizable and may be specific to local populations.

We believe that PEPR should be incorporated and prescribed as part of optimal care post-discharge following an exacerbation [13, 22], which may increase acceptability and access to patients. In this study, the team delivering PEPR met patients during their inpatient stay, which may have increased acceptance rates. To enhance the feasibility of PEPR in clinical practice, transport should be provided to ensure frail patients can access the service, as was the case in this study.

In this quality improvement project, patients with an exacerbation of any chronic respiratory condition were accepted into the PEPR program. Other published data only accepted patients following an AECOPD. Guidelines recommend PR for all chronic respiratory conditions [11, 19], and it is likely that both the feasibility and cost effectiveness of PEPR will be increased by including patients with an exacerbation of any chronic respiratory condition. In our study, 10 out of 112 referred patients had respiratory conditions other than COPD. Some service models incorpo- 
rate PEPR into standard (elective) PR programs. However, clinical supervision is crucial, and due to increased breathlessness, anxiety, and potential medical instability, post-exacerbation patients are likely to require closer supervision and support to exercise at adequate and safe levels. They also may have more complex health needs and require ambulatory oxygen or walking aid in the follow-up of hospitalization. It may, therefore, be appropriate to provide PEPR as a stand-alone program rather than attempting to integrate post-exacerbation patients into existing PR programs. Patients admitted with AECOPD are at higher risk of further exacerbations. Therefore, a small window of opportunity exists to recruit patients to PEPR post-discharge, to ensure that physiological benefits are achieved before reexacerbation.

\section{PEPR effectiveness}

In this study, PEPR resulted in improved exercise tolerance and QoL. Furthermore, we demonstrated that outcomes observed in RCTs can be replicated in a local general hospital population. In our study, we observed that maximal exercise capacity improved beyond the minimal clinically important difference (MCID). However, previous RCTs $[9,10]$ investigating PEPR observed greater improvements in maximal exercise tolerance than was measured in this investigation. Previous RCT cohorts reported a lower baseline exercise tolerance and less severe airway obstruction than this cohort, and therefore previous cohorts had greater scope for improvement, which may explain the lesser improvement observed in this cohort.

This is the first study investigating PEPR to use BPQ, CAT, and HADS as outcome measures. This was a quality improvement project where less time-consuming outcome measures were utilized. We are therefore unable to make direct comparisons with previous studies [8-10]. However, significant improvements in QoL and health status were observed in this study, which, despite the different outcome measures utilized, appear to be in concordance with previous studies. Overall, the baseline scores for anxiety and depression were low, indicating no mood disturbances [23], which may explain why there was no observed statistical improvement. However, there was a reduction in the number of patients with abnormal or increased levels of anxiety and depression following PEPR, and this should be considered clinically relevant. This is the first study considering the impacts of PEPR on psychological wellbeing, and future larger studies could provide further insight.

\section{Patient perspective}

Previous RCTs and clinical studies have not reported on patients' perspectives of PEPR. This study found that patients perceived PEPR to be beneficial, and that they valued both the exercise and education elements. Further studies into why patients accept or decline PEPR may help to inform service design and improve patients' uptake of PEPR.

\section{Limitations, bias, and confounding factors}

This study reports on a real-life clinical application of PEPR. Subsequently, there was no control group. Instead, PEPR decliners and drop-outs were utilized as a comparison group. The patients in the PEPR decliner group were self-selected. It was not possible to collect baseline demographics on many of these patients, making study entry comparison difficult. Those patients who declined may have done so due to a more severe disease, poor motivation, higher levels of anxiety, a more complex disease, or a high number of comorbidities. Patients who dropped out from PEPR attended too few sessions to achieve physiological health benefits from the program. However, the fact that these patients had completed some PEPR sessions may have created a confounding factor. Drop-out patients' data were analyzed along with the PEPR-decliner patients, making the analysis more susceptible to attrition bias but providing a better estimate of treatment effects. As this was a quality improvement project, it was not feasible to blind patients, staff, or those conducting the analysis. The lack of blinding in this study may have caused some bias, however the main aims of the study was to consider 
the feasibility of PEPR in a real-world example. Patient perspective in this study was a secondary outcome, the patient survey was not piloted, and we acknowledge that data collection of patients' perspectives did not follow the usual rigor of qualitative research.

\section{Future action}

There is much debate in the respiratory specialization regarding the feasibility of PEPR in clini- cal practice. As part of our quality improvement work, and using the results of this and other studies, we have considered potential causes for low PEPR completion rates. Figure 3 shows a cause-and-effect fishbone diagram, which considers necessary changes to the PEPR program provided in this study, as well as changes for other clinicians to consider when implementing a PEPR program.

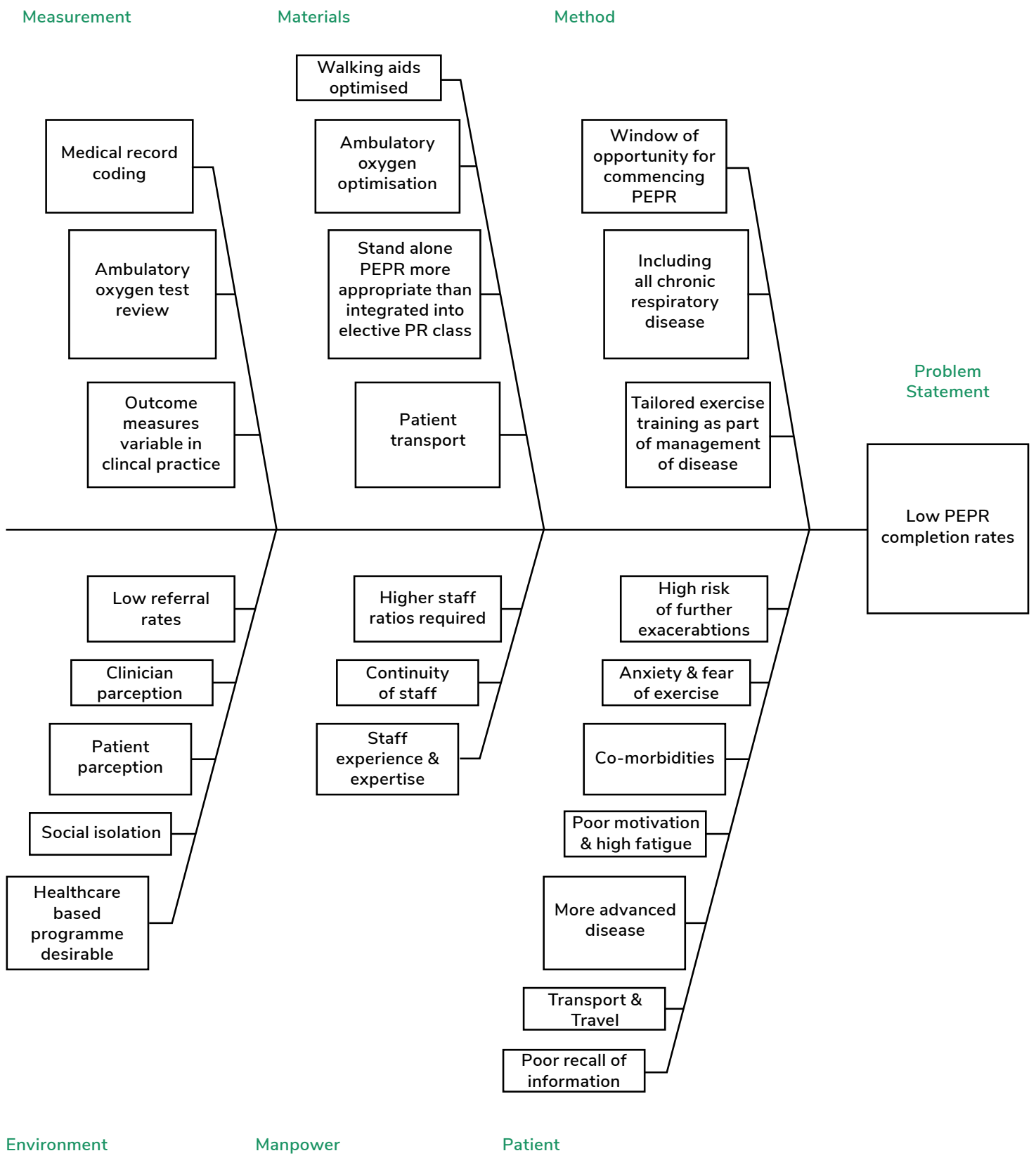

Figure 3. Factors contributing to the low Post-Exacerbation Pulmonary Rehabilitation (PEPR) completion rates. 


\section{Conclusion}

This quality improvement project has demonstrated that it is feasible to implement PEPR in clinical practice. It would appear from the results of this project that, in the local population studied, PEPR is a cost-effective treatment option in the management of exacerbations of chronic respiratory disease. The results of this real-world quality improvement project suggest that the benefits of PEPR on exercise tolerance, health status, and QoL observed in RCTs and meta-analyses can also be replicated in clinical practice.

\section{Abbreviations}

30ED - 30-day Emergency Department attendance;

90ED - 90-day Emergency Department attendance;

30R - 30-day readmissions;

90R - 90-day readmissions;

AECOPD - Acute Exacerbations of Chronic Obstructive Pulmonary Disease;

ASPH - Ashford and St Peter's Hospitals NHS

Foundation Trust;

ATS - American Thoracic Society;

BPQ - Breathing Problem Questionnaire; CAT -

COPD Assessment Test;

ERS - European Respiratory Society;

ESWT - Endurance Shuttle Walk Tests;

$\mathrm{FEV}_{1}$ - Forced Expiratory Volume in one second;

FVC - Forced Vital Capacity;
HADS - Hospital Anxiety and Depression Score;

HC - Healthcare;

ICER - Incremental Cost Effectiveness;

ISWT - Incremental Shuttle Walk Test;

LSS - Length of Stay;

NHS - National Health Service;

PEPR - Post-Exacerbation Pulmonary Rehabili-

tation;

QoL - Quality of Life;

RCT - Randomised Controlled Trial;

$\mathrm{VO}_{2}$ peak - Peak Oxygen consumption.

\section{Acknowledgements}

The authors would like to acknowledge the contribution of Suzanne Storr and Harriet Black to the implementation of the programme and data collection. Furthermore, the authors would like to thank Dr. John Hurst and Dr Stefan Tino Kulnik for their assistance in preparing this manuscript for publication. Finally, the authors would like to acknowledge the assistance of Musharrat Ahmed-Landeryou in the cost effectiveness analysis.

\section{Financial support}

Funding was secured from the chief executive's innovation fund, Ashford and St Peter's Hospitals (ASPH) NHS Foundation Trust to pilot PEPR in a bid to reduce readmission rates.

\section{References}

1. NICE. Chronic Obstructive Pulmonary Disease: Management of chronic obstructive pulmonary disease in adults in primary and secondary care. In: National Institute of Health and Clinical Excellence, editor. London: National Institute of Health and Clinical Excellence; 2010.

2. Department of Health. An outcome strategy for COPD and Asthma: NHS companion document. In: 22 HEALTH DO, editor. London 2012.
3. Spruit M, Gosselink R, Troosters T, Kasran A, Gayan-Ramirez G, Bogaerts P, et al. Muscle force during an acute exacerbation in hospitalised patients with COPD and its relationship with CXCL8 and IGF-I. Thorax. 2003; 58 (9): 752-756.

4. Cote CG, Celli BR. Predictors of mortality in chronic obstructive pulmonary disease. Clin Chest Med. 2007; 28 (3): 515-524. 
5. Schmier JK, Halpern MT, Higashi MK, Bakst A. The quality of life impact of acute exacerbations of chronic bronchitis (AECB): a literature review. Qual Life Res. 2005; 14 (2): 329-347.

6. Garcia-Aymerich J, Farrero E, Felez MA, Izquierdo J, Marrades RM, Anto JM. Risk factors of readmission to hospital for a COPD exacerbation: a prospective study. Thorax. 2003;58(2):100-5

7. García-Sanz MT, Cánive-Gómez JC, Senín-Rial L, et al. One-year and long-term mortality in patients hospitalized for chronic obstructive pulmonary disease. J Thorac Dis. 2017; 9 (3): 636-645.

8. Puhan MA, Gimeno-Santos E, Scharplatz M, Troosters T, Walters EH, Steurer J. Pulmonary rehabilitation following exacerbations of chronic obstructive pulmonary disease. Cochrane Database Syst Rev. 2011; 10 (10): CD005305.

9. Seymour JM, Moore L, Jolley CJ, Ward K, Creasey J, Steier JS, et al. Outpatient pulmonary rehabilitation following acute exacerbations of COPD. Thorax. 2010;65(5):423-8.

10. Man WD, Polkey MI, Donaldson N, Gray BJ, Moxham J. Community pulmonary rehabilitation after hospitalisation for acute exacerbations of chronic obstructive pulmonary disease: randomised controlled study. BMJ 2004; 329 (7476): 1209.

11. Bolton CE, Bevan-Smith EF, Blakey JD, et al. British Thoracic Society guideline on pulmonary rehabilitation in adults. Thorax. 2013; 68 Suppl 2: ii1-ii30.

12. Man WD, Puhan MA, Harrison SL, Jordan RE, Quint JK, Singh SJ. Pulmonary rehabilitation and severe exacerbations of COPD: solution or white elephant? ERJ Open Res. 2015; 1 (2): 00050-2015.

13. Jones SE, Green SA, Clark AL, Dickson MJ, Nolan A-M, Moloney $\mathrm{C}$, et al. Pulmonary rehabilitation following hospitalisation for acute exacerbation of COPD: referrals, uptake and adherence. Thorax. 2013; 69 (2): 181-182.

14. Harrison S, Robertson N, Graham C, Williams J, Steiner M, Morgan M, et al. Can we identify patients with different illness schema following an acute exacerbation of COPD: A cluster analysis. Respir Med. 2014; 108 (2): 319-328.
15. Fleming S, Jones S, Green S, Clark A, Howe C, Kon S, et al. P43 Patients' experiences of early post-hospitalisation pulmonary rehabilitation: A quality improvement initiative. Thorax. 2013; 68 (Suppl 3): A94-A.

16. Zaidi F, Bracken N, Norwick L, Coultas D, Casaburi R, Rand C, et al. Patient Perspectives And Barriers To Pulmonary Rehabilitation Following Hospitalizations For Chronic Obstructive Pulmonary Disease Exacerbations. Am J Respir Crit Care Med. 2015; 191: A2222.

17. Congleton J, Wookey J, Bott J. P30 Use Of A Regional Copd Dashboard To Effect Large Scale Change J Congleton, J Wookey, J Bott Kss Ahsn Respiratory Programme. Thorax. 2014; 69: A90-A91.

18. Langley GJ, Moen RD, Nolan KM, Nolan TW, Norman CL, Provost LP. The improvement guide: a practical approach to enhancing organizational performance: John Wiley \& Sons; 2009.

19. Spruit MA, Singh SJ, Garvey C, ZuWallack R, Nici $\mathrm{L}$, Rochester C, et al. An official American Thoracic Society/European Respiratory Society statement: key concepts and advances in pulmonary rehabilitation. Am J Respir Crit Care Med. 2013; 188 (8): e13-e64.

20. Miller MR, Hankinson J, Brusasco V, Burgos F, Casaburi R, Coates A, et al. Standardisation of spirometry. Eur Respir J. 2005; 26 (2): 319-338.

21. Hyland M, Singh S, Sodergren S, Morgan M. Development of a shortened version of the Breathing Problems Questionnaire suitable for use in a pulmonary rehabilitation clinic: a purpose-specific, disease-specific questionnaire. Qual Life Res. 1998; 7 (3): 227-333.

22. Jones SE, Green SA, Clark AL, Dickson MJ, Nolan A-M, Moloney $\mathrm{C}$, et al. Pulmonary rehabilitation following hospitalisation for acute exacerbation of COPD: referrals, uptake and adherence. Thorax. 2014; 69 (2): 181-182.

23. Harrison S, Greening N, Williams J, Morgan M, Steiner M, Singh S. Have we underestimated the efficacy of pulmonary rehabilitation in improving mood? Respir Med. 2012; 106 (6): 838-844.

24. ed. 2013; 188 (8): e13-e64. 